\title{
Polar Sport Tester for Cattle Heart Rate Measurements
}

\author{
Marjan Janzekovic, Peter Vindis, Denis Stajnko and Maksimiljan Brus \\ University of Maribor, Faculty of Agriculture and Life Sciences \\ Slovenia
}

\section{Introduction}

Well-being and health status of the animal in relations to achieving optimal production, become a standard when grading intensive livestock systems. Heart rate and body temperature have traditionally been used as parameters for different animal species health assessment, since they can indicate a problem with the animal. Also, interest for stressrelated research increased in the last decades, resulting in many available techniques, but as stated by (Janczarek, 2009) the simplicity and practical applicability for the average user should be taken into account. According to (Hopster, 1998; Janzekovic, 2005; Aerts et al., 2008) the change of heart rate can be a relevant parameter, when studying the response of the animal to stress. This is in correlation with findings in the humane medicine that variability of the heart rate serves as an important mechanism of the adaptation capability.

Reaction of heart is viewed as an objective way of representing the autonomous responses of the nervous system to psychological stressors, associating increased and decreased heart rates with the predominant influence of sympathetic or parasympathetic nervous systems. Challenges of the environment activate both branches of the autonomous nervous system. This induces changes in the frequency of the heart rate, which is viewed as the index of the psychological influence of outside events (Herd, 1991). Recent findings also demonstrated direct hard-wired linkage between control of cardiac function and animal response (Lefcourt et al., 1999).

Most important stimuli for variations in heart rate generally are excitement, stress, exercise, or some kind of altered physical homeostasis. Because of this, focus in research has always been to investigate and monitor changes in the mentioned parameters, aiming to get a strong correlation with health status. This resulted in invention of special devices which rely on heart rate as certainly the most practical means for judging animal's status.

Heart rate monitors have been developed for purpose of fitness in human and equine athletes, but have evolved into modern health status measuring devices. This equipment became recommended and highly advocated tool in illness, disease, or stress diagnostics. Because of accuracy of measurements with Polar Sport Tester (best accuracy in comparison with ECG) (Macfarlane et al., 1989; Hopster \& Blokhuis, 1994; Lefcourt et al., 1999) the said finding was taken into account to a greater extent in the analysis of the data of our test. 


\subsection{Heart rate as indicator of stress state of cattle}

Measurement of heart rate is one of most common used non-invasive methods for gathering physiological parameters of stress. From the point of animal welfare it has major advantage over traditionally used blood sample test techniques (Janzekovic et al., 2006). Heart frequency, implying the number of heart contractions per minute (bpm) is mainly measured, as it has a good correlation as indicator for impending problems in the animal. This advocates resting heart rate which represents measurement in relaxed condition when animal is calm, but attention must be taken since sometimes this is very hard and can mask elevated values meaning also masking the potential health problem. Depending from environment, the heart frequency is different and varies from animal to animal. Monitoring of the heart rate and its variability is, from the technical side, very complicated and impractical to measure in situations like milking, transport, or calving. Likewise in barns with the free housing system of breeding of milking cows (Janzekovic et al., 2005) it is impossible with meters and/or devices to be put onto animals. In our preliminary test that was found out already during the time of habituation of animals to wearing adapted measuring devices. The cows, freely moving about, mutually took off or tore from the body the elastic straps, simulating the girth belt with transmitter, already during the first seconds of wearing. In the milking parlour they had not enough time to focus on straps and it took only a short time until they have accustomed themselves to them with the use of a simulated girth belt (Janzekovic et al.,2005). (Hopster, 1998) also noticed a similar effect during the period of accustoming to wearing the measuring equipment. On animals in groups it is possible to measure the heart rate for a longer time only by means of implants with transmitter under the skin. For this reason use of the electrocardiography pill for cattle was investigated by (Warren et al., 2008), to provide veterinarians with data to assess cattle state without the need to physically restrain it. Nevertheless much work is still to be done concerning its practical applicability.

With the introduction of automatic milking systems the interest for reliable and practical measuring of stressful situations, implicating health status and production of the animal, increased (Gygax et al., 2008). As stress is mainly expressed by plasma cortisol concentrations and heart rate variation (Schmidt et al., 2010), the decision to use noninvasive measuring technique of heart rate (HR) on cows in tandem milking parlour was made based on this and results presented in many studies describing methods of heart rate measure on different categories of animals. Tests dealt with telemetric recording of surface electrocardiograms (Kovalcik et al., 1988; Lay et al., 1992; Royle et al., 1992.), and most of the research has been done in the field of equine exercise physiology by means of Polar heart rate monitors like »Horse Tester« and »Polar Equine« (Evans et al., 1986; OldruitenbourghOOsterbaan et al.,1988, Art et al., 1993; Gygax et al., 2008; Kedzierski \& Janczarek, 2009; Leleu et al., 2005). New solutions include complete wireless HR equipment systems, and findings show that these devices play an important role in diagnostics, and sometimes even enable health problem prevention and certainly on time intervention and clinical checking for further treatment from responsible personnel. It should be taken into account that not all values (like recovery heart rate) can be used and compared with research in human athletes, since differences between species exist. Elevation of heart beats without any notable environmental challenge can only be marked as internal health problem or even lameness like seen in horses (Foreman \& Lawrence, 1991).

(Karvonen et al., 1984) report that telemetric devices for measuring the heart rate on humans during the sports activity are also suitable for transmitting the signal from animals, freely 
moving about or tied. Researchers (Seaward et al., 1990; Royle et al., 1998; Knierim \& Waran, 1993; Hopster, 1998) also measured the heart rate on milking cows and other categories of cattle with various types of adapted telemetric devices from the heart rate meter sets of the Finnish maker Polar Electro Oy, which have also been used as measuring equipment in our research.

\section{Modification of measuring device}

Methods for checking heart rate have undergone a significant change with advancement in the latest technology. For many years, simple palpation of the artery was used, but it always had a potential subjective error. This was also the case for stethoscope, besides better accuracy in determining normal and higher heart rates, but still not enough practical when monitoring maximal heart rate and minimizing human handling and restrain stress on the mentioned. Recently all of those began to be replaced with electronic heart rate monitors which measure electrical pulses of the heart, and which were widely tested during exercise in horses. Since it boosted better performance and training techniques in equine sports, practical applicability was also investigated in other farm and wild animals, like cows, pigs and reindeers (Hopster \& Blokhuis, 1994; Seo et al., 1998; Eloranta et al., 2002).

For measuring the heart rate special apparatuses, used by top sportsman during training, were tested. This was, particularly, the heart rate meter "Polar Sport Tester-Profi" (PST) made by the Finnish maker of equipment Polar Electro Oy. The meter is equipped with a transmitter and elastic belt with movable holder and with an intermediate unit for connection to the computer "Polar Interface". Taking into account the $70 \mathrm{~cm}$ length of the elastic belt the mentioned device could be located only on sucking and weaned calves of up to $180 \mathrm{~kg}$ body mass. With the lengthened belt, into which simply the transmitter was inserted, periodical response was obtained during testing on the animals of up $280 \mathrm{~kg}$ body mass only, if the electrolyte was added between the animal's skin and the sensor. The response was slightly better after the hairs have been removed from the skin at the place where the electrodes were located. On animals weighing more than $280 \mathrm{~kg}$ the desired response was not reached. By further modifications of the Polar device the distance between the two electrodes was increased and, thus, the response was achieved also on adult cattle (Janzekovic et al., 2006; Ploj et al., 2006; Mursec \& Cus, 2003).

The elastic belt with transmitter was located round the animals' thorax. The used type of the transmitter has two electrodes of $20.7 \mathrm{~cm}^{2}$ size installed in a tightly closed frame. The two electrodes are $9 \mathrm{~cm}$ long so that the ECG signal can be reliably recognized. That design ensures complete water-tightness. It has ribbed surface for better contact with the skin. The two electrodes are $9 \mathrm{~cm}$ distant from each other. On the calf the first electrode was located on the left side between the shoulder-blade and back areas and at 3 to $4 \mathrm{~cm}$ below the control back line. The second electrode was located in the area of the sternum. If the two electrodes and the two places of their locating on the skin were wetted with ordinary water, better conductivity between the skin and the two electrodes was reached. The heart beat signal was telemetrically transmitted to the hand receiver which was worn on the hand and later on fixed to the girth belt. The receiver calculated the heart beats on the basis of the time average algorithm between two consecutive heart beats and counted in 5, 15 or 60s intervals (Seaward et al., 1990). For measurements the apparatuses were set to the 5 second interval. The first read off value was calculated from the first 4 values of the heart beat (Hopster, 1998). With the use of the maker's computer programme (programme package Polar HR Analysis, version 4.10) the data were 
electronically transferred to the personal computer (Mursec et al., 2000; Mursec et al., 2006; Janzekovic et al., 2005; Janzekovic et al., 2005; Cus \& Mursec, 2004; ).

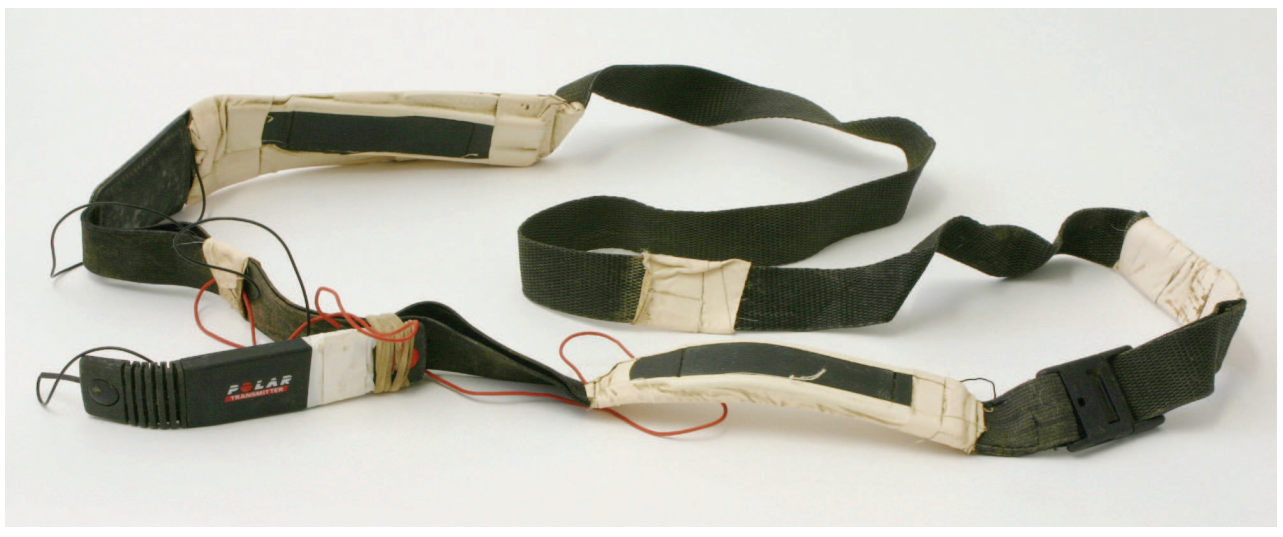

Fig. 1. The alteration on girth belt with Polar Sport Tester transmitter adjusted by the author

By increasing the distance between the two electrodes it was, thus, possible to obtain continuous signal also on adult animals. Care must be taken to place them on the chest of the animal below and above the heart, taking care that the negative one is placed below, but all the time priority must be to put them as far as possible from each other. Usually sweat provides sufficient contact, but since its production depends on environmental factors and sometimes can be unpredictable, water or special electrolyte mixture between skin and electrodes advisable to secure the conductivity. Instead of the incorporated Polar transmitter from the Sport Tester-Profi set the transmitter with two separated electrodes Polar Sport Tester was used. The two electrodes were connected with two wires and connecting buttons. On a specially made elastic belt for fixing of electrodes it was possible to change the distance between the two electrodes according to the size of the animal (Figure 1).

\subsection{The possibility of heart rate measurements in cattle with the updated equipment}

The measurements are possible also with Polar Equine RS800CX G3 (Figure 2) horse training system (Polar Electro Oy, Kempele, Finland) on the cattle. At the moment some measurements are investigated on different categories of cattle. The electrical heart signals that in-struct the heart to beat and create contraction can be measured on the skin by means of two electrodes of the Polar Equine T56 W.I.N.D. transmitter. This coded, wire-less textile transmitter has ECG accuracy and sends data even over $5 \mathrm{~m}$ distance to the receiver for further analyses or storage. Electrodes are placed on the chest of the horse below and above the heart, taking care that the negative one is placed below, but all the time caution must be taken to put them as far as possible from each other. Usually sweat provides sufficient contact, although water or special electrolyte mixture has been used to secure the conductivity. The set also included Polar G3 GPS Sensor which tracks the route on mapping software, like Google Earth. It enables record of altitude, speed and distance, likewise with the software provided color change was possible on the route trajectory when heart rate intensity and workload was altered. This makes it the most complete heart-rate based training solution for horses, which accents its importance in the era of GPS introduction and usage in biomedicine (Aerts el al., 2008; Hebenbrock et al., 2005). 


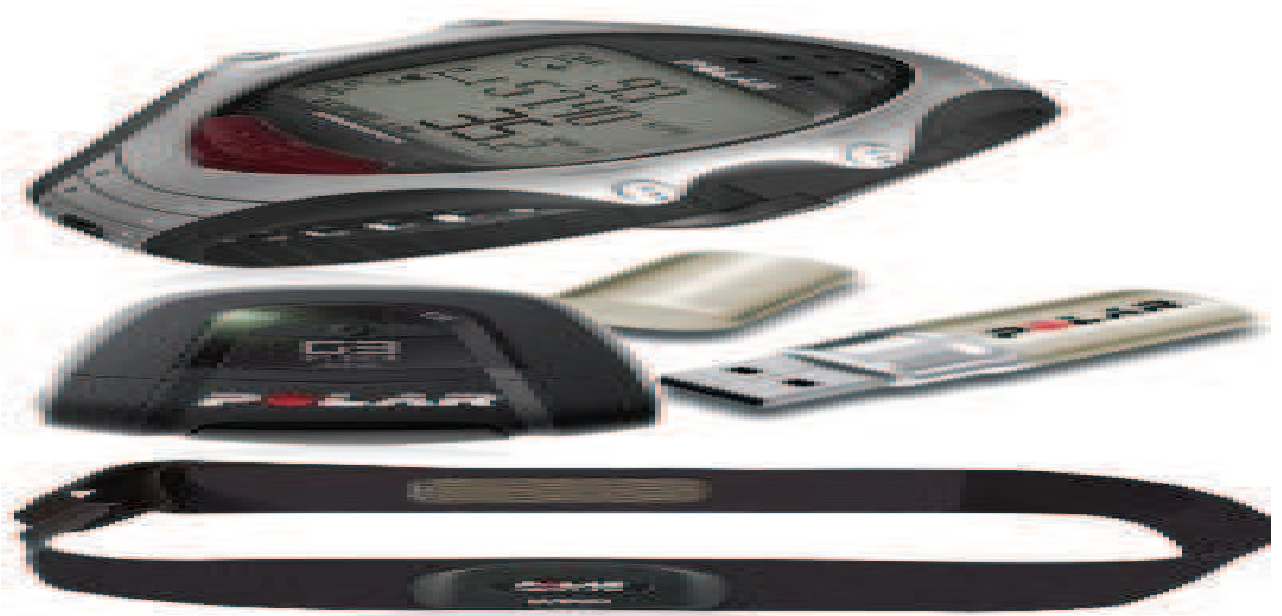

Fig. 2. State of art equipment for heart rate measurements Polar Equine RS800CX G3 horse training system, including receiver, transmitter, GPS sensor, and software

\subsection{Test measurements}

In our test the cows' heart rate depended on various influences: farm (A and B), individual cow, consecutive lactation (2, 3 and 4$)$, consecutive measurements $(M=1,2,3)$, morning and evening milking $(\mathrm{M}=1 ; \mathrm{E}=2)$. As an example, Figures 3 and 4 show the processes of the HR on milking cows No. 3 (3 consecutive lactation) and No. 4 (2 consecutive lactation) from the herd on the farm A.

Taking into account the differences in the process of the heart rate it can be concluded that the influence on the HR is conditional upon the individual responsiveness of the cow. The average HR of six units of measurements (Table 1) was 75.05 beats per minute on the cow

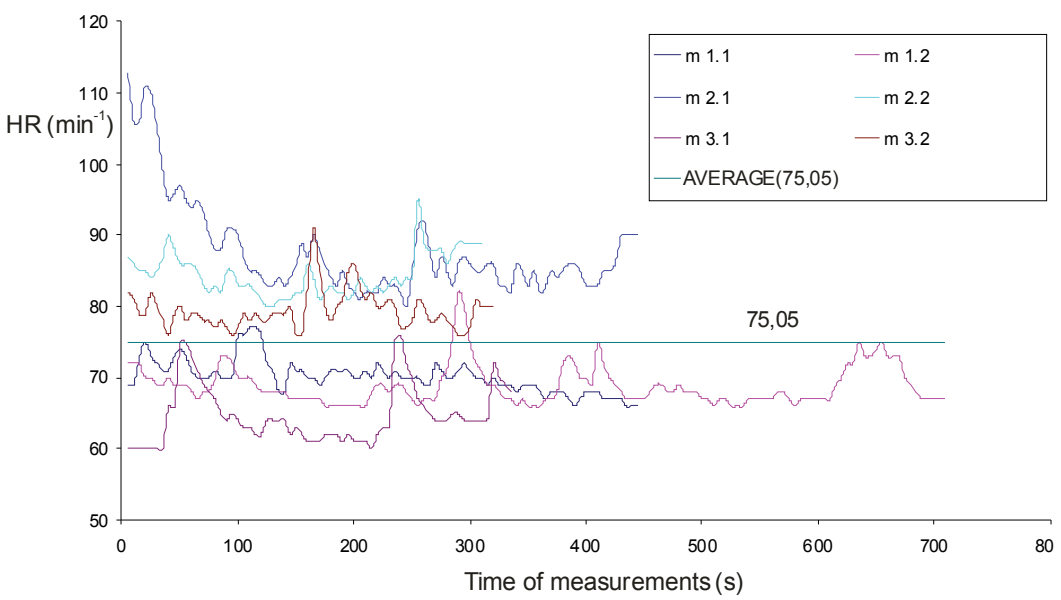

Fig. 3. Measured heart rates of milking cow No. 3 and average of measurements 


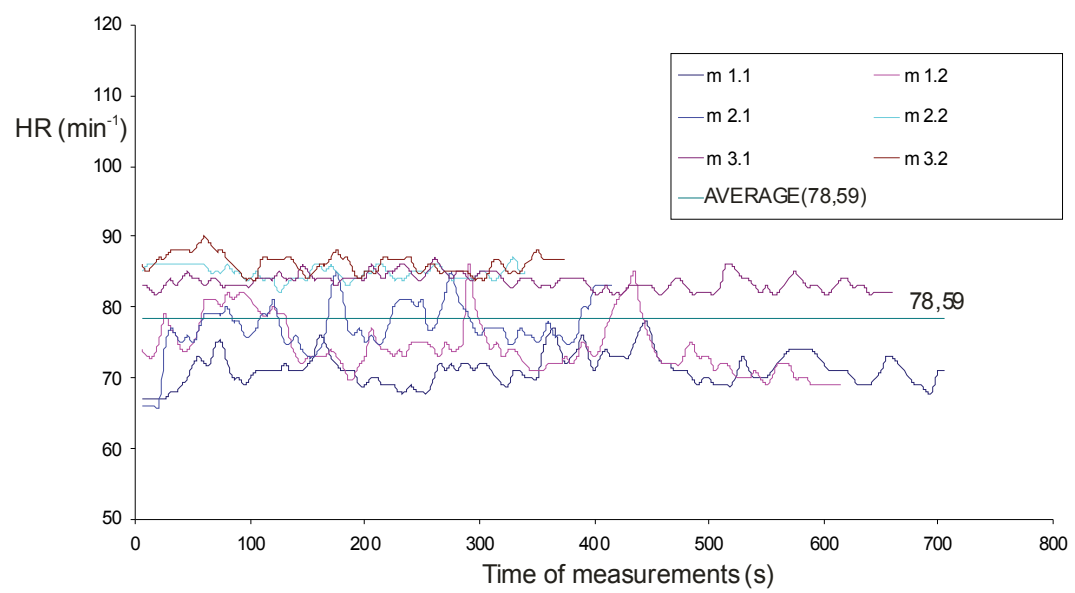

Fig. 4. Measured heart rates of milking cow No. 4 and average of measurements

\begin{tabular}{|l|c|c|}
\hline & Cow 3 & Cow 4 \\
\hline Total number of measurements & 513 & 622 \\
\hline Average of heart rate $\left(\mathrm{min}^{-1}\right)$ & 75.05 & 78.59 \\
\hline SD & 9.27 & 6.27 \\
\hline CV $(\%)$ & 12.35 & 7.98 \\
\hline SEM & 0.41 & 0.25 \\
\hline
\end{tabular}

Table 1. Basic statistics of the heart rate on cow No. 3 and No. 4 taking all measurements into account

No. $3(\mathrm{SD}=9.27$; SEM = 0.41) and 78.59 beats per minute on the cow No. 4 (SD = 6.27; SEM = 0.25). In spite of high variability of the HR during each measurement, which was $12.35 \%$, on the cow No. 3 and $7.98 \%$, on the cow No. 4, the two average values are comparable.

Research on comparing telemetric and ECG data showed essentially identical heart rates, differing only less than $5 \mathrm{bpm}$, which were mainly the result of depending how average heart rate was calculated (Lefcourt et al., 1999). Nevertheless, changes can happen momentarily, and attention is required in interpretation results in the means of delay time between computed PST values and rapid heart rate alteration. This is in correlation with present study and even more signifies the importance of HR monitors, likewise advantage of averaging responses.

Among the milking cows there were also differences in the quantity of the milk produced and its composition on the day of measurements as shown in Table 2.

The cow No. 4, during three consecutive measurements (M1, M2, M3) produced $31.2 \mathrm{~kg}$ of milk daily on the average $(\mathrm{FCM}=27.79 \mathrm{~kg}$; $\mathrm{ECM}=23.77 \mathrm{~kg})$, which is $5.3 \mathrm{~kg}$ more than the cow No. 3 that, on the average, produced $25.9 \mathrm{~kg}$ of milk daily at the time of three consecutive measurements $(\mathrm{FCM}=30.73 \mathrm{~kg}$; $\mathrm{ECM}=29.31 \mathrm{~kg})$. Higher daily milk production relies on greater need for nutritive substances from the feed ration. In the same time, intensive digestion and metabolism take place in the animal's organism, which, consequentially, can influence the heart rate. In relations to this, research by (Seo et al., 1998) shows that tongue-playing caused as developing stereotype in calves, has a de-arousal function to reduce sympathetic nervous activity especially after feeding and consequent metabolic processes, and by that way also influence heart rate. 


\begin{tabular}{|l|c|c|c|c|c|c|c|c|}
\hline \multirow{2}{*}{$\begin{array}{c}\text { Measured } \\
\text { property }\end{array}$} & \multicolumn{4}{|c|}{ Cow 3 } & \multicolumn{4}{c|}{ Cow 4 } \\
\cline { 2 - 10 } & M1 & M2 & M3 & Average & M1 & M2 & M3 & Average \\
\hline Milk (kg/day) & 23.8 & 28.0 & 26.0 & 25.9 & 32.0 & 32.6 & 29.0 & 31.2 \\
\hline Milk fat (\%) & 4.96 & 4.47 & 4.46 & 4.63 & 4.20 & 3.64 & 3.86 & 3.90 \\
\hline FCM (kg/day) & 27.23 & 29.97 & 27.79 & 28.33 & 32.96 & 30.84 & 28.39 & 30.73 \\
\hline Milk protein (\%) & 3.08 & 3.14 & 3.00 & 3.07 & 3.24 & 3.13 & 3.03 & 3.13 \\
\hline ECM (kg/day) & 21.86 & 26.34 & 23.11 & 23.77 & 31.29 & 30.55 & 26.10 & 29.31 \\
\hline Milk sugar (\%) & 4.42 & 4.40 & 4.60 & 4.47 & 4.62 & 4.36 & 4.58 & 4.52 \\
\hline
\end{tabular}

$\mathrm{FCM}=$ fat corrected milk to $4 \%$ of milk fat

$\mathrm{ECM}=$ protein corrected milk to $3.3 \%$ of milk proteins

Table 2. Properties of milk production during complete measurements on cows 3 and 4

On the cow No. 3 the fat content in milk during the average of three consecutive measurements was higher for 0.73 percental point in comparison with the milking cow No. 4, whereas, conversely, the protein content was greater on the milking cow No. $4(3.13 \%)$. Both milk sugar contents were lower than the average contents $(4.7 \%)$ started in technical literature. Variations of the average lactose contents are not in accordance with the expected values depending on the process of lactation itself. Generally in mammals heart frequency increases or decreases for 4.5 beats per minute with respect to each breathing motion independently of the body mass. The body mass of cows can have an effect on the heart frequency through breathing frequency which can amount to 15 to 30 breathing motions per minute on the cow in lactation. Numbers of heart beats are also influenced by cows' reactions, in the first place by previous milking experience. With every consecutive parity and increasing age, pressure is on higher milk yield, putting greater physiological demand on the animal. Because of this, likewise possible accumulation of negative milking experience, and changes in immune status (somatic cell counts), potential effect could be in metabolism.

On the first successful insemination the cow No. 4 was 58 days younger than the cow No. 3 and $88 \mathrm{~kg}$ lighter (Table 3). The difference compels us to think that lighter and younger cows with the first calf are maybe more stressed during their later productive period and, therefore, have higher heart rate.

\begin{tabular}{|l|c|c|}
\hline \multicolumn{1}{|c|}{ Established values } & Cow 3 & Cow 4 \\
\hline First successful insemination (days) & 542 & 484 \\
\hline Height of withers & 136 & 128 \\
\hline Height of the back $^{*}$ & 138 & 131 \\
\hline Length of trunk $^{*}$ & 140 & 130 \\
\hline Thorax circumference $^{*}$ & 202 & 184 \\
\hline Calculated body mass (kg) $^{*}$ & 566 & 478 \\
\hline
\end{tabular}

*- measured in cm on cows with first calf

Table 3. Age of cows 3 and 4 on the first successful insemination and body dimensions of cows with the first calf

During the evening milkings average heart rate on the milking cow No. 3 and No. 4 was higher than during the morning milking. The heart rate of milking cows was measured during three followed up morning milkings: 74.23 beats per minute on the milking cow No. 
3 and 77.34 beats per minute on the milking cow No. 4. During three evening milkings the milking cow No. 3 had 77.60 measured beats per minute, whereas the milking cow No. 4 had 81.87 beats per minute. According to one of the interpretations the found out measurement results can be attributed to fluctuations in the warmth production and, consequently, in the milking cow body temperature (Purwanto et al., 1990) depending, particularly, on the age of the animal, sex, season, ambient temperature, muscular activity, feed consuming, digestion and drinking of water. The normal rectal temperature of the milking cows amounts to $38.6^{\circ} \mathrm{C}$ with 38.0 to $39.3^{\circ} \mathrm{C}$ range. On the Holstein cows the rectal temperature starts to increase already at $21^{\circ} \mathrm{C}$ ambient temperature, which is associated with the decrease in appetite and milk production. Intensively fed animals have somewhat higher temperature than the cows fed more poorly (Purwanto et al., 1990). According to the digestion increases the body temperature for 0.2 to $1{ }^{\circ} \mathrm{C}$, followed by an increase in heart frequency (Rozman et al., 2006). Also from the measured heart rates of cow No. 3 and No. 4 it can be concluded that higher HR during the evening milking is partly a consequence of more active metabolism and/or higher ambient temperature during the afternoon time. Also as shown in study by (Gygax et al., 2008) all milking systems result in higher HR values during milking than during resting, and more specifically vagal tone (related to temperament and stress vulnerability; strongly reflects short-term, high-frequency components of heart rate variability) is lower in cows with higher milk production. Since milking process is stressful itself, should be expected to have higher values during it, and decreased vagal tone and elevated heart rates are remarked during milking as compared to resting.

\section{Adapted PST apparatuses in milking parlour}

As previously mentioned there is influence of milking systems on various physiological parameters. Even cow handling (in the means of free or guided traffic) has some influence on the heart rate values (Gygax et al., 2008). During milking in the milking parlour surprising results were achieved in measuring the HR by modified Polar Sport Tester apparatuses in production conditions with 27 cows (Table 4).

The reached data were processed in the statistical package SAS/STAT 1996 (Cary, 1996).

\begin{tabular}{|l|c|c|c|c|}
\hline \multicolumn{1}{|c|}{ Property } & $\mathrm{N}$ & Average & $\mathrm{SD}$ & $\mathrm{KV}(\%)$ \\
\hline Milk production (kg/milking) & 162 & 13.03 & 3.46 & 26.55 \\
\hline Duration of milking (s) & 162 & 407.8 & 65.24 & 16.00 \\
\hline Speed of consuming (g/min) & 162 & 249.7 & 59.12 & 23.68 \\
\hline Consumed DM (kg/milking) & 162 & 2.14 & 0.85 & 39.72 \\
\hline HR $\left(\mathrm{min}^{-1}\right)$ average per milking & 161 & 82.38 & 11.55 & 13.85 \\
\hline HR $\left(\mathrm{min}^{-1}\right) 1$ - 30 s & 161 & 84.70 & 13.16 & 15.54 \\
\hline HR $\left(\mathrm{min}^{-1}\right)$ middle of milking & 156 & 82.18 & 11.99 & 14.59 \\
\hline HR $\left(\mathrm{min}^{-1}\right)$ last 30 s & 111 & 82.20 & 11.23 & 13.66 \\
\hline
\end{tabular}

$\mathrm{HR}=$ heart rate; $\mathrm{DM}=$ dry meal; $\mathrm{SD}=$ standard deviation; $\mathrm{KV}=$ coefficient of variability; $\mathrm{N}=$ number of measurements

Table 4. Statistical parameters for milk production, duration of milking and consumption of concentrate; mean value, standard deviation and coefficient of variability for heart rate during milking 
New technologies in dairy industry, in the first place use of automatic milking systems, affected research in relevant scientific fields. This is also accounted for welfare of the animal, and study by (Gigaw et al., 2008) comparing these two figures concluded that there is no serious impairment of the welfare when milking cows in automatic milking systems.

\subsection{Relations between the average HR process and the variability coefficient}

During the first two minutes of milking the process of variability of the average HR (Figure 5) was followed up with the variability coefficient. The average HR during milking increased during the first 20 seconds when it reached the highest value $85.14 \pm 1.10$ beats per minute $(\mathrm{r}=0.9859 ; \mathrm{P}=0.0141)$, SD 13.92 beats per minute; then during the next 15 seconds it dropped to the average value $83.63 \pm 0.98(\mathrm{r}=-0.8387 ; \mathrm{P}=0.0184)$, SD 12.41 beats per minute; afterwards it becomes slightly stable until the 50th second when from the value 83.53 beats per minute it drops until the 95 second to the lowest value $82.24 \pm 0.93$ beats per minute $(\mathrm{r}=-0.9642 ; \mathrm{P}<0.0001)$, SD 11.86 beats per minute. between 95 and 110 seconds it is possible to see a slight increase in the HR to $82.71 \pm 0.97$ beats per minute $(\mathrm{r}=-0.9283 ; \mathrm{P}<$ $0.0001)$, SD 12.28 beats per minute. From the 111th second onwards again dropping until the 120th second is noticed in case of 159 measurements performed. During this duration of milking the average HR amounted to $82.47 \pm 0.98$ beats per minute $(r=-0.9127 ; \mathrm{P}<0.0001)$, SD 12.35 beats per minute.

After the first 5 seconds $(t=5 \mathrm{~s})$ of measuring and/or duration of milking the value $\mathrm{KV}=$ $16.47 \%$, which is a higher value than $\mathrm{KV}=11.30 \%$ calculated from the value in case of the normal range of the HR of adult cattle, which, according to amounts to 60 to 80 beats per minute. Since in the same time we have to do also with increased average value of the HR it can be concluded that parallel factors influence these two properties. After 10 seconds a tendency towards reduction of variability for $0.26 \%$ is noticeable; afterwards during 15 seconds of milking it stabilizes itself again to the initial value $(\mathrm{KV}=16.47 \%)$.

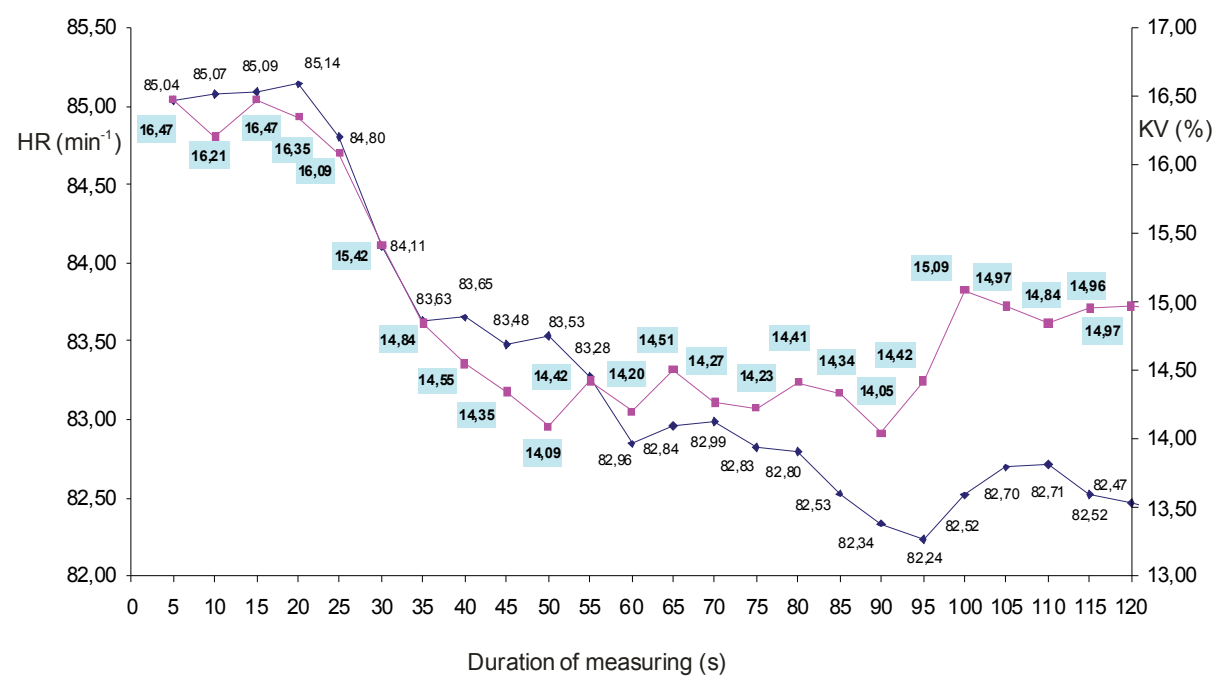

Fig. 5. Process of HR and variability coefficient during the first 120 seconds of milking 
That drop of the value of the variability coefficient could indicate the events before the start of milking (prestimulation of udder, secretion of oxytocin, consuming the offered feed concentrate), which, consequentially, still influenced the process of value of the HR (increasing during the first 20 seconds) and the variability coefficient in the beginning of milking. Due to differently long prestimulation time probably also a delay in responsiveness of the value of the variability coefficient occurred, when the actual transition into the steep drop of the variability coefficient took place prior to the drop of the average HR value. The tendency towards the drop of variability did not stop at the 35 second level, where the HR value calmed down, but that happened only in case of 50 seconds with the value $14.09 \%$. At that time the drop of the variability coefficient amounted to $0.07 \%$ per second on the average. The HR value in the beginning of the calming down level during the 35th second amounted to 83.65 beats per minute and the drop during the time between the 20th and 35th second amounted to $0.02 \%$, i.e., 1.51 beat per minute. From the 35th to 50th second the HR calmed down at the value 83.53 beats per minute followed by a rather steep drop within 10 seconds to the value 82.96 beats per minute. From the 60 th to the 80 th second of milking the HR was near the value 82.90 beats per minute; afterwards it decreased again and, at the 90th second, it reached the value 82.24 beats per minute. The motion of the variability coefficient up to the 90th second is in dynamic variation within the values 14.51 to $14.05 \%$, which is the lowest calculated value of the KV. From the 90th second of milking onwards the variability coefficient steeply increases again for about $1 \%$, followed with 5 second delay by gradual increase of the HR to the value 82.70 beats per minute at the 105th second, where it remains at the same value level until the repeated drop at the 110th second, which practically follows the previous drop of the KV with 10 second delay.

From the described process of the HR and KV it can be presumed that the greater decrease or increase of the KV value (over the $1 \%$ ) with shorter or longer delay was followed by an increase or decrease in the average HR value. In our case, the beginning of the change of the curve progress (drop or rise) is a matter of variability as clearly shown in Figure 5 here below, whereas reaching the calming down level is a matter of the HR.

\subsection{Comparison and testing of differences in correlation values of HR process with milking time and variability coefficient}

Figure 6 shows the relations between the process of the average HR values and the time of milking and progress of coefficients of correlations between the HR, KV of the heart frequency and the time of milking.

After the first 20 seconds of milking the time of milking and the HR frequency are highly positively related $(\mathrm{r}=0.986 ; \mathrm{P}=0.0141)$, whereas during the same time interval the statistically significant degrees of relatedness between the time of milking and the heart rate $\mathrm{KV}$ were not found $(\mathrm{r}=-0.107 ; \mathrm{P}=0.893)$. Herebelow the tendency towards repeated increase of high negative relatedness of the heart frequency as well as the KV with the time of milking is indicated.

Highly significant relatedness between the heart frequency and the time of milking can, then, be traced up to the 120th second, although gradual constant exchanging of the increase and decrease of relatedness up to its maximum value in the 95th second of milking $(\mathrm{r}=-$ 0.964; $\mathrm{P}<0.0001$ ) is followed by a turning point indicating the process of the increase of the average value of the HR between the 95th and 110th second. After the 120th second the relatedness of the heart frequency to the time of milking is still always significantly negative $(\mathrm{r}=-0.916 ; \mathrm{P}<0.0001)$. After 35 seconds the $\mathrm{KV}$ is significantly highly negatively related 


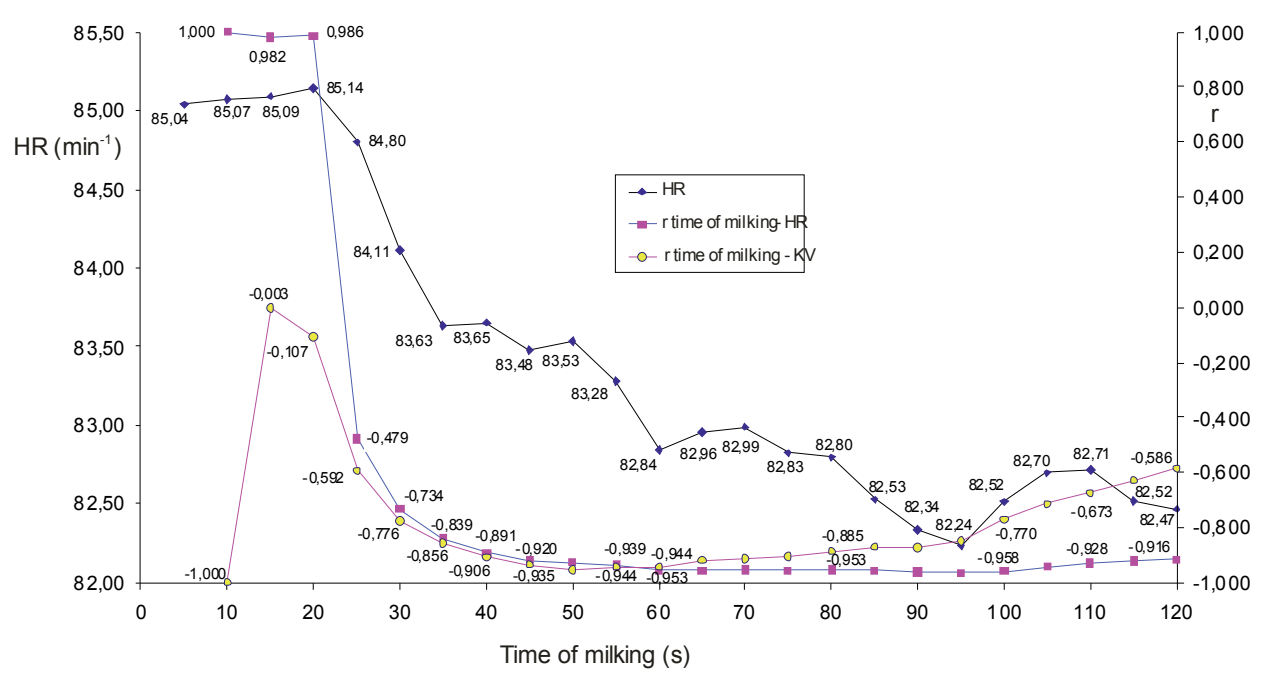

Fig. 6. Process of average HR value during the first 120 seconds of milking, coefficient of correlation $(\mathrm{r})$ between $\mathrm{HR}$, heart rate $\mathrm{KV}$ and time of milking

with the duration of milking $(\mathrm{r}=-0.856 ; \mathrm{P}=0.014)$ up to the 50th second of milking when it reaches the maximum relatedness $(\mathrm{r}=-0.952 ; \mathrm{P}<0.0001)$ near the relation of the time of milking to the HR. Between the 50th and 60th second the parallelism of the process of both coefficients of correlations with the time of milking is interrupted, the negative relatedness between the time of milking and the KV decreases (the KV increases again) and at the 120th second of milking it reaches only one half or so of the greatest relatedness $(\mathrm{r}=-0.586 ; \mathrm{P}=$ 0.003. the degree of relatedness of the KV of the heart frequency only approaches zero, the positive relatedness with the time of milking can be traced only on sections where the negative relatedness decreases.

Figure 7 shows the process of the correlation coefficient and the coefficient of partial correlation between the average value of the HR and its variability (KV) during milking. During the initial 20 seconds of milking the actual relatedness of the HR and its variability is negative and insignificant $(\mathrm{r}=-0.663$; $\mathrm{P}=0.368)$; it is possible to trace the transition into positive relatedness between the 20th and 25th second, which coincides with the change of the process of the heart frequency and its variability (see Figure 4). The highest relatedness was noticed after the 35th second of milking $(\mathrm{r}=0.952 ; \mathrm{P}=0.0016)$, then it decreases and after the 65th second it reaches the lowest value after the turning point $(\mathrm{r}=0.709 ; \mathrm{P}=$ 0.0059). Then up to the 120th second of milking the heart frequency and its variability have the tendency towards the positive relatedness $(\mathrm{r}=0.903 ; \mathrm{P}<0.0001)$.

As the heart dynamics is usually monitored by the nervous system (Peng et al., 1993) and also by hormonal influences, this would imply that the sound heart as an example of arousable medium incorporates a mechanism responsible for prevention of the extremes of the heart rhythm. The change of the dynamics of the heart frequency is probably also a consequence of the changed hormonal status in the organism, when the udder stimulation during the time prior to milking is transmitted through nervous stimuli over the hypothalamus into the hypophysis where the hormone oxytocin is secreted from the neurohypophysis into blood; its secretion is additionally stimulated by consumption of the 
feed concentrates through gastrointestinal hormones. According to these authors the increased concentrations of the injected oxytocin have an effect on the heart rate blood pressure and minute volume; this was reflected in our test in such a way that from the 60th second onwards during milking the HR values were no longer normally distributed.

Also the non-planned fall of a cow into the milking canal confirmed that the HR can be one of important indicators of stress state of the animals. Upon the fall the average HR of 205 beats per minute was measured, which represents $218 \%$ of the average of the same cow during other evening milkings. Here, a considerable deviation from the preceding state of the heart rate frequency was concerned, which, however, cannot be a parameter for establishing the influence of stress in case of apparently healthy animals, when in answer to occurrence of metabolic trouble, i.e. acidosis, the sympathic nervous system, acting on the haemodynamic variables, is activated: the contractability of the heart muscle, the heart rate and the minute volume are increased.

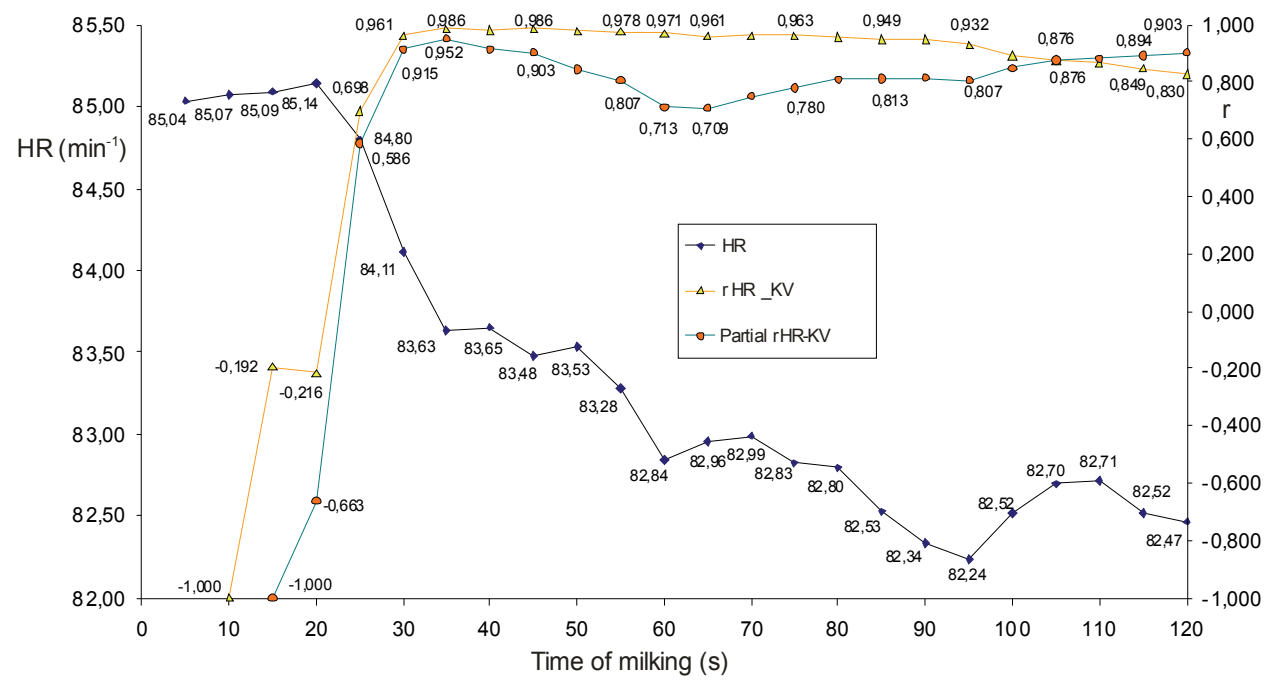

Fig. 7. Process of average heart rate value during the 120 seconds of milking, correlation coefficient (r) and coefficient of partial correlation (partial r) between HR and KV of HR during milking

\section{Conclusion}

The use of measuring of the heart frequency as an indicator of stress in the course of feeding milking cows with concentrates in the milking parlour is recommendable only conditionally, namely for the cases when the healthy animals have available balanced basic ration and a sufficient quantity of feed concentrates. The used methods of following up the process of milking, e.g., measuring of the electric activity of the oxytosynergic nervous cells, changes in intramammary pressure, concentration of oxytocin in blood and recording of the milk flow characteristics, could be complemented by a more non-invasive method, e.g., measuring of heart frequency so that more precise and, particularly, faster following up of the events before and during milking would be introduced, based on good familiarization 
with the changes of the heart rhythm features and correct evaluation of influences on their change.

Variability of the HR can indicate individual response to the stress and vulnerability due to stress. The study shows that the PST values importantly reflect the HR frequency and its variability; therefore, we have concluded that the PST is adequate for measuring the heart rate and the variability of the HR on milking cows.

The process of the correlation coefficients shows that in our case, up to 25th second of milking, a dynamic turning point of relatedness between the HR, KV and partial relatedness of the HR and KV with the milking process are in question. Another obvious change took place during that time between the 55th and 65th second of milking. In our test, during the first two minutes of milking, the average value of the heart frequency was more related with the time of milking than its variability.

According to our findings, the measured properties of the HR during the first 5 and 120 seconds of milking had the smallest variability on the cows in the fourth consecutive lactation; the highest variability was recorded on cows in the third consecutive lactation, producing the greatest average quantity of milk during each milking, with the highest fat content and the lowest content of proteins and lactose.

In consideration of the mentioned relationship between the amount of concentrate and HR, our assumption is that cows could not consume all available concentrate and for that reason the HR was elevated. The analysis of the data with D' Agostino - Pearson test of normality suggests that distribution of the heart rate was changed between 60 and 65 second of milking and was continually persistent up to 120 second of milking. The nondirectional alternative hypotesis supported at 0.001 level cleary suggests that the data sets of heart rate were not derived from a normally distributed population between 60 and 65 second and furthermore, between 95 and 100 second of milking. The assessment of heart rate measurement provides several advantages over blood measurements as the measuring procedure is non-invasive and stress-free, making it ideal for use on healthy animals like a physiological indicator of stress and in psychoneuroendocrinological research.

\section{References}

Aerts, J.M. ; Gebruers, F. ; Van Camp, E. ; Berckmans, D. (2008). Controlling horse heart rate as a basis for training improvement, Computers and electronics in Agriculture, 64, 7884

Art, T. \& Lekeux, P. (1993). Training-induced modifications in cardiorespiratory and ventilatory measurements in thoroughbred horses, Equine Veterinary Journal, 25 532-536.

Cus, F. \& Mursec, B. (2004). Databases for technological information systems, Journal of Materials Processing Technology, 157/158, 75-81

Eloranta, E. ; Norberg, H. ; Nilsson, A. ; Pudas, T. ; Sakkinen, H. (2002). Individually Coded Telemetry : a Tool for Studying Heart Rate and Behavious in Reindeer Calves, Acta veterinaria scandinavica, 43, 135-144

Evans, D.L. \& Rose, R.J. (1986). Method of investigation of the accuracy of four digitallydisplaying heart rate meters suitable for use in the exercising horse, Equine Veterinary Journal, 18, 129-132

Foreman, J.H. \& Lawrence, L. (1991). Lameness and heart rate elevation in the exercising horse, Journal of equine veterinary science, 11, 353-356 
Gygax, L. ; Neuffer, I. ; Kaufmann, C. ; Hauser, R. ; Wechsler, B. (2008). Restlessness behaviour, heart rate and heart-rate variability of dairy cows milked in two types of automatic milking systems and auto-tandem milking parlours, Apllied Animal Behaviour Science, 109, 167-179

Hebenbrock, M.; Due, M.; Holzhausen, H.; Sass, A.; Stadler, P.; Ellendorff, F. (2005). A new tool to monitor training and performance of sport horses using Global Positioning System (GPS) with integrated GSM capabilities, Dtsch. Tierarztl. Wschr., 112, 241 280

Herd J.A. (1991). Cardiovascular response to stress, Physiological Reviews, 71, 305-330

Hopster, H. (1998). Coping strategies in dairy cows, Dissertation Thesis, Agricultural University Wageningen, Wageningen, 152

Hopster, H. \& Blokhuis, H.J. (1994). Validation of a heart-rate monitor for measuring a stress response in dairy cows, Canadian Journal of Animal Science, 74, 465-474

Janczarek, I. (2009). Connections between the heart rate and selected motor and biometric parameters in young half-bred stallions, Annales Universitatis Mariae CurieSklodowska, Section EE, Vol. XXVII (1), pp 27-36

Janzekovic, M. (2005). Measuring heart rate of cows in milking parlour, Agricultura, 3, 21-25

Janzekovic, M. ; Mursec, B. \& Janzekovic, I. (2005). Development of noninvasive method of measuring of heart rate in cattle, Proceedings of the 4th DAAAM International Conference on Advanced Technologies for Developing Countries, Vienna DAAAM International, pp 523-528, Mechanical Engineering Faculty, Slavonski Brod, Croatia

Janzekovic, M. ; Janzekovic, I. \& Mursec, B. (2005). Researches and applicability of noninvasive method of measuring of heart rate in cattle, Annals of DAAAM for 2005 $\mathcal{E}$ proceedings of the 16th International DAAAM symposium, Vienna DAAAM International, pp 173-174, University of Rijeka, Opatija, Croatia

Janzekovic, M. ; Mursec, B. \& Janzekovic, I. (2006). Techniques of measuring heart rate in cattle, Technical Gazete, 13, 31-37

Janzekovic, M. ; Mursec, B. ; Cus, F. ; Ploj, A. ; Janzekovic, I. ; Zuperl, U. (2005). Use of machines for liquid manure aerating and mixing, Journal of Materials Processing Technology, 162-163, 744-750

Janzekovic, M. ; Janzekovic, I. \& Mursec, B. (2005). Following up heart rate in cattle by noninvasive method, DAAAM International scientific book 2005, pp 291-298, DAAAM International Vienna, Austria

Karvonen, J. ; Chwalbinska-Moneta, J. \& Saynajakangas, S. (1984). Comparison of heart rates measured by ECG and microcomputer, Physician and Sportsmedicine, 12, 65-69

Kedzierski, W. \& Janczarek, I. (2009). Sex-related effect of early training on stress in young trotters as expressed by heart rate, Animal Science and Reports, vol 27, no 1, 23-32

Knierim, U. \& Waran, N.K. (1993). The influence of the human-animal interaction in the milking parlour on the behaviour, heart-rate and milk yield of dairy cows, Proceedings of the international congress on applied ethology, Humboldt University, Berlin, 169-173

Kovalcik, K. ; Kovalcikova, M. \& Broucek, J. (1988). Interbreed differences in the responses of first-calvers to artificially induced stress conditions, Scientia Agriculturae Bohemoslovaca, 20, 203-209 
Lay, D.C. Jr. ; Friend, T.H. ; Grissom, K.K. ; Hale, R.L. ; Bowers, C.L. (1992). Novel breeding box has variable effects on heart rate and cortisol response of cattle, Applied Animal Behaviour Science, 35, 1-10

Lefcourt, A.; Erez, B. ; Varner, M.A.; Barfield, R.; Tasch, U. (1999). A Nonivasive Radiotelemetry System to Monitor Heart Rate for Assessing Stress Responses of Bovines, Journal of Dairy Science, 82, 1179-1187

Leleu, C. ; Cotrel, C. \& Courouce-Malblanc, A. (2005). Relationships between physiological variables and race performace in French standardbred trotters, Veterinary Record, 156, 339-342

Macfarlane, D.J. ; Fogarty, B.A. \& Hopkins, W.G. (1989). The accuracy and variability of commercially available heart rate monitors, The New Zealand Journal of Sports Medicine, 17, 51-53

Mavrin, D. \& Ostir, S. (2002). Technology of milk and milk products, Technical publishing company of Slovenia, Ljubljana, 27-51

Mursec, B. \& Cus, F. (2003). Integral model of selection of optimal cutting conditions from different databases of tool makers, Journal of Materials Processing Technology, 133, 158-165

Mursec, B. Cus \& F. Balic, J. (2000). Organization of tool supply and determination of cutting conditions, Journal of Materials Processing Technology, 100, 241-249

Mursec, B. ; Janzekovic, M. ; Cus, F. ; Zuperl, U. (2006). Comparison of rollers after sowing of buckwheat, Journal of achievements in materials and manufacturing engineering, 17, 269-272

Peng, C.K. ; Mietus, J. ; Hausdorff, J.M. ; Havlin, S. ; Stanley, H.E. ; Goldberger, A.L. (1993). Long-range anticorrelations and non-gaussian behavior of the heartbeat, Physical Review Letters, 70, 1343-1346

Ploj, A. ; Mursec, B. ; Cus, F. ; Zuperl, U. (2006). Characterization of machines for processing of waste materials, Journal of Materials Processing Technology, 175, 338-343

Purwanto, B.P. ; Abo, Y.; Sakamoto, R. ; Furumoto, F. ; Yamamoto, S. (1990). Diurnal patterns of heat production and heart rate under thermoneutral conditions in Holstein Friesian cows differing in milk production, Journal of Agricultural Science, $114,139-142$

Rietmann, T.R. ; Stuart, A.E.A. ; Bernasconi, P. ; Stauffacher, M. ; Auer, J.A. ; Weishaupt, M.A. (2004). Assessment of mental stress in warmblood horses: heart rate variability in comparison to heart rate and selected behavioural parameters, Applied Animal Behaviour Science, 88, 121-136

Royle, C. ; Garnsworthy, P.C. ; McArthur, A.J. ; Mepham, T.B. (1992) Heart rate changes in dairy cows associated with milking, Journal of Physiology, 446-575

Rozman, C. ; Pazek, K. ; Bavec, M. ; Bavec, F. ; Turk, J. ; Majkovic, D. (2006). The Multicriteria analysis of spelt food processing alternatives on small organic farms, Journal of sustainable agriculture, 28, 159-179

SAS/STAT 1996. Users Guide, Cary, SAS Institute

Seaward, B.L. ; Steamaker, R.H.; McAuliffe, T. ; Clapp, J.F. (1990). The precision and accuracy of a portable heart rate monitor, Biomedical Instrumentation and Technology, 24, 37-41

Seo, T. ; Sato, S. ; Kosaka, K. ; Sakamoto, N. ; Tokumoto, K. (1998). Tongue-playing and heart rate in calves, Apllied Animal Behaviour Science, 58, 179-182 
Schmidt, A. ; Mostl, E. ; Wehnert, C. ; Aurich, J. ; Muller, J. ; Aurich, C. (2010). Cortisol release and heart rate variabilities in horses during road transport, Hormones and Behavior, 57, 209-215

van Oldruitenborgh-Oosterbaan, M.M.S. ; Hoven, R. \& Breukink, H.J. (1988). The accuracy of the different heart rate meters used for studies in the exercising horse, Journal of Veterinary Medicine, 35, 665-672

Visser, E.K. ; van Reenen, C.G. ; van der Werf, J.T.N. ; Schilder, M.B.H. ; Knaap J.H. ; Barneveld A. ; Blokhuis H.J. (2002). Heart rate and heart rate variability during a novel object test and handling test in young horses, Physiology \& Behavior, 76, 289296

Warren, S. ; Martinez, A. ; Sobering, T. ; Andresen, D. (2008). Electrocardiographic Pill for Cattle Heart Rate Determination, 30th Annual International IEEE EMBS Conference 


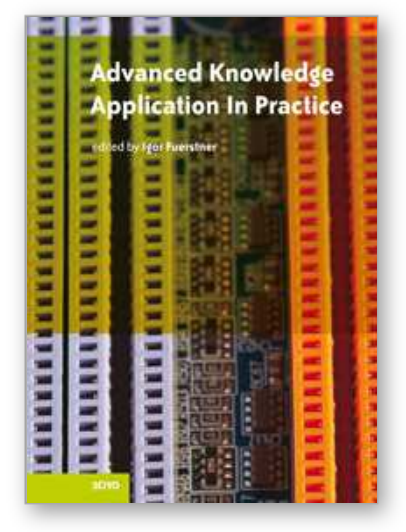

\author{
Advanced Knowledge Application in Practice \\ Edited by Igor Fuerstner
}

ISBN 978-953-307-141-1

Hard cover, 378 pages

Publisher Sciyo

Published online 02, November, 2010

Published in print edition November, 2010

The integration and interdependency of the world economy leads towards the creation of a global market that offers more opportunities, but is also more complex and competitive than ever before. Therefore widespread research activity is necessary if one is to remain successful on the market. This book is the result of research and development activities from a number of researchers worldwide, covering concrete fields of research.

\title{
How to reference
}

In order to correctly reference this scholarly work, feel free to copy and paste the following:

Marjan Janzekovic, Peter Vindis, Denis Stajnko and Maksimiljan Brus (2010). Polar Sport Tester for Cattle Heart Rate Measurements, Advanced Knowledge Application in Practice, Igor Fuerstner (Ed.), ISBN: 978-953307-141-1, InTech, Available from: http://www.intechopen.com/books/advanced-knowledge-application-inpractice/polar-sport-tester-for-cattle-heart-rate-measurements

\section{INTECH}

open science | open minds

\author{
InTech Europe \\ University Campus STeP Ri \\ Slavka Krautzeka 83/A \\ 51000 Rijeka, Croatia \\ Phone: +385 (51) 770447 \\ Fax: +385 (51) 686166 \\ www.intechopen.com
}

\author{
InTech China \\ Unit 405, Office Block, Hotel Equatorial Shanghai \\ No.65, Yan An Road (West), Shanghai, 200040, China \\ 中国上海市延安西路65号上海国际贵都大饭店办公楼405单元 \\ Phone: +86-21-62489820 \\ Fax: $+86-21-62489821$
}


(C) 2010 The Author(s). Licensee IntechOpen. This chapter is distributed under the terms of the Creative Commons Attribution-NonCommercialShareAlike-3.0 License, which permits use, distribution and reproduction for non-commercial purposes, provided the original is properly cited and derivative works building on this content are distributed under the same license. 